\title{
Tolerance Constraints on Reliability Analysis of Gear System
}

\author{
Li Guo-wei, Lu Kai-liang and Zhang Wei-guo \\ Logistics Engineering College, Shanghai Maritime University, \\ guoweimy2008@163.com
}

\begin{abstract}
To improve the reliability of a product performance the tolerancing problem may not be neglected especially for miniature precise assembly device. The purpose of this paper is to explore an approach to evaluate the reliability of gear system considering the influence of tolerance constraints. The paper describes the principle and ways of tolerance handling in the finite element control equations, and then introduces the implementation steps based on Monte-Carlo FEA method. The resonance reliability analysis of a gear-tooth system of portcleaning-equipment gear pump is carried out to illustrate the mentioned method, and a sensitivity analysis is also performed to identify the key tolerances and improve them in order to achieve the anticipated reliability.
\end{abstract}

Keywords: Tolerance constraints, Reliability analysis, Resonance reliability sensitivity, Gear system, FEA, Port-cleaning-equipment

\section{Introduction}

It is a great challenge for product development to guarantee the reliability of performance in view of product complexity and harsh working conditions. To improve the reliability of a product performance the tolerancing problem may not be neglected especially for miniature precise assembly device. To evaluate the impact of tolerance on product quality, much research has been conducted over the past years: L. Pierre and his partners described how thermomechanical strains are integrated into tolerancing analysis and how they influence the controlling clearance between the tips of the high pressure turbine blades and the stator [1]. $\mathrm{Xu}$ performed performance analysis of the reheat-stop-valve mechanism under dimensional tolerance, misalignment and thermal impact [2]; Manarvi and Juster used finite element method to simulate the effect of tolerance on part deformation [3]; Serban and his partner studied the effect of manufacturing tolerances on the low-noise amplifier performance by means of sensitivity analyses [4]. However, present studies of tolerance analysis are more concerned with assembly quality and the motion characteristics of specific mechanism, the reliability analysis of miniature precise assembly device simultaneously considering working condition and manufacturing tolerance is seldom studied.

Gear transmission system is used widely in modern products, which usually require low noise, long life, high reliability as well as best price. The changing of actual working condition and the existing manufacturing deviation cause wearing condition of gear tooth flank or vibration in process of gears meshing, therefore it is important to carry out reliability analysis. Q. Q. Wang studied the reliability of gear random vibration system and transmission error [5]; Y. N. Wang and his partners carried out the resonance reliability sensitivity analysis considering the influence of temperature on the gear structure mode [6].

In this paper, tolerance as a random variable was taken into account in the Finite Element Analysis (FEA) on pump gear system, firstly the handling method of tolerance in the finite 
element control equations was proposed; Secondly the reliability analysis method using Monte Carlo-based Finite Element Methods (FEM) was put forward, and a sensitivity analysis is also performed to identify the key tolerances and improve them aims to achieve the anticipated reliability. Therefore, the tolerance constraints on reliability analysis will provide the designer with an analysis model closer to reality.

\section{Handling Method of Tolerance in Finite Element Control Equations}

In mechanical engineering, engineer needs predications of stiffness and elastic deformation of components. The deformation results from forces and moments under operating conditions as well as from residual stress of press fits as a superposition of both [7]. Displacements in the contact area (Figure 1a) have their cause in tolerance specifications and other factors (Figure 1b). FEA model is always based on various assumptions and idealized conditions despite the fact that material properties, manufacturing tolerances, boundary conditions and working conditions are uncertain, which results in a greater difference between the calculation results and the actual condition [8]. Therefore, the influence of irregularities of manufactured part surfaces to the residual stress of fitting parts should be taken into the FEA calculation method.

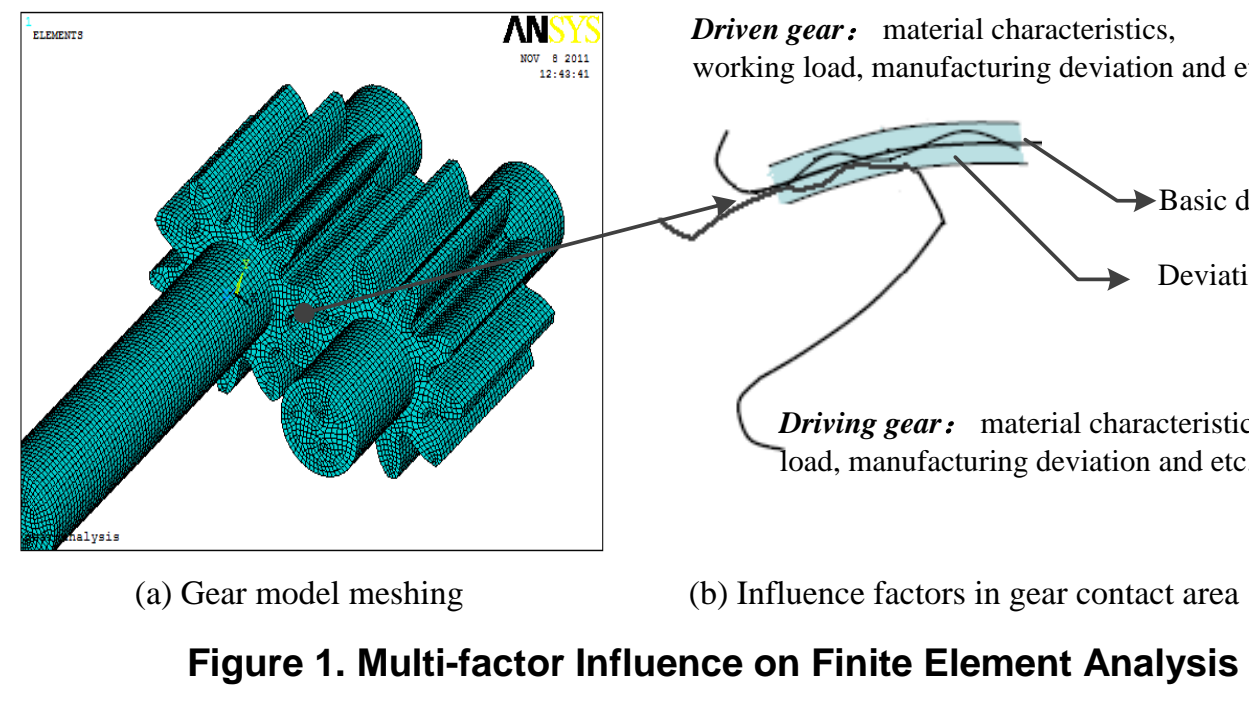

According to the basic theory of Stochastic Finite Element [9], the displacement and stress finite element equations can be derived as follows:

According to the principle of virtual displacements and stress-strain relations, the nodal equilibrium equation can be expressed by displacement:

$$
[\mathbf{K}][\mathbf{U}]=[\mathbf{F}]
$$

Where $\mathrm{K}$ is the known stiffness matrix of the system, $\mathrm{U}$ is the vector of displacements or rotations and $\mathrm{F}$ is the vector of external forces or moments.

The system of equations can be transformed in the following way:

$$
[\mathbf{U}]=[K]^{-1}[F]
$$

In terms of the stress- strength interference theory, stress - strain relations can be expressed in the following equation:

$$
[\boldsymbol{\sigma}]=[D][\varepsilon]=[\mathbf{D}][\mathbf{B}][\mathbf{U}]
$$

Where $\sigma$ is the vector of stress, $\mathrm{D}$ is material elastic matrix, $\varepsilon$ is strain vector. 
With the aid of (2) and (3), we can calculate $\sigma$ and $\varepsilon$. At the assumption of K, F and D are the function of random variable $X=\left(X_{1}, X_{2}, \cdots, X_{\mathrm{m}}\right)$, the number of variable is $\mathrm{m}$, then $\mathrm{U}$ and $\sigma$ can be expressed with $X$ as follows:

$$
\begin{aligned}
& U(X)=U\left(X_{1}, X_{2}, \cdots, X_{m}\right) \\
& \sigma(X)=\sigma\left(X_{1}, X_{2}, \cdots, X_{m}\right)
\end{aligned}
$$

Where random variables $X$ include various loads, part geometric parameters and physical parameters (Poisson's ratio, elastic modulus E, thermal expansion coefficient, etc.).

Based on Monte-Carlo method, a groups of random variables that were randomly selected from $m$ mutual independence variables $\left(X_{1}, X_{2}, \cdots, X_{\mathrm{m}}\right)$ are listed as $X_{1}=\left(X_{11}, X_{21}, \cdots, X_{\mathrm{m} 1}\right)$, then $\mathrm{U}$ and $\sigma$ can be calculated in the following way after $\mathrm{N}$ groups of variables were selected:

$$
\left\{\begin{array}{c}
U\left(X_{1}\right)=U\left(X_{11}, X_{21}, \cdots, X_{m 1}\right) \\
U\left(X_{2}\right)=U\left(X_{12}, X_{22}, \cdots, X_{m 2}\right) \\
\cdots \\
U\left(X_{n}\right)=U\left(X_{1 n}, X_{2 n}, \cdots, X_{m n}\right)
\end{array},\left\{\begin{array}{c}
\sigma\left(X_{1}\right)=\sigma\left(X_{11}, X_{21} \cdots, X_{m 1}\right) \\
\sigma\left(X_{2}\right)=\sigma\left(X_{12}, X_{22}, \cdots, X_{m 2}\right) \\
\cdots \\
\sigma\left(X_{n}\right)=\sigma\left(X_{1 n}, X_{2 n}, \cdots, X_{m n}\right)
\end{array}\right.\right.
$$

The statistical characteristic of $\{U\}$ and $\{\sigma\}$ can be obtained from the above statistics, when product performance is expressed as a function of $\mathrm{U}$ or $\sigma$, the reliability of product performance can be calculated based on the function of $\mathrm{U}$ or $\sigma$.

As for the natural frequency of gear system, which has much to do with the structural dimension, material and working conditions, manufacturing deviation also exerts influence on the natural frequency. Therefore, the resonance reliability analysis could be closer to reality if the effect of tolerance has been taken into the calculation of natural frequency.

The gear will be failed or damaged due to resonance vibration when the self-exciting frequency $f$ is equal or close to the natural frequency $f_{0 i}$.

The natural frequency can be expressed as follows:

$$
f_{0 i}=y\left(X_{1}, X_{2}, \cdots, X_{m}\right) \quad(i=1,2, \cdots, n)
$$

Where $f_{0 i}$ represents the $i$ order natural frequency.

The self-exciting frequency as active driven gear and driven gear meshing can be expressed in the following equation:

$$
f=n \times Z / 60
$$

Where $n$ is the rotation speed, $Z$ is the number of gear teeth.

When the resonance vibration happened, i.e. $f$ is equal or close to $f_{0 i}, Z_{-\bmod a l}$ is defined as output target and the range of resonance vibration failure is set at $Z_{-\bmod a l} \leq 0.01$ :

$$
Z_{-\bmod a l}=\left(\left|f-f_{0}\right| / f\right) \times 100 \%
$$

According to the basic principle of reliability analysis, the resonance reliability can be expressed as the probability equation $P_{S}=P\left[Z_{-\bmod a l} \leq 0.01\right]$.

However, the geometric dimension of parts would be regarded as a random variable for the reliability analysis of product performance, so it is necessary to establish the constraint relation between dimensions and tolerances, the methods used were as follows:

First of all, parts dimension allowed values can be expressed as $x \pm \Delta x$ where $\mathrm{x}$ is basic dimension, $\pm \Delta x$ is the upper and lower tolerance. The dimensional variables generally obey the Gaussian distribution. According to " $3 \sigma_{x}$ principle" in statistics, parts dimension mean $\mu$ and standard deviation $\sigma_{x}$ can be expressed in the following way[10]: 


$$
\mu=x, \quad \sigma_{x} \approx \frac{(\bar{x}+\Delta x)-(\bar{x}-\Delta x)}{6}=\frac{\Delta x}{3}
$$

Secondly, when parts dimension ranges from $x_{\max }$ to $X_{\min }$, then $\mu$ and $\sigma_{x}$ can be expressed in the following way:

$$
\mu=\frac{x_{\min }+x_{\max }}{2}, \quad \sigma_{x}=\frac{x_{\max }-x_{\min }}{6}
$$

In addition, " $3 \sigma_{x}$ principle" is also applied to other random variables, i.e. the standard deviation $\left(\sigma_{x}\right)$ can be determined by the scope of parameters.

\section{Implementation of Reliability Analysis based on Monte Carlo-FEA}

The reliability calculation and analysis can be implemented through the combination of FEA and Monte-Carlo method (Figure 2). The content mainly includes: firstly, the threedimensional CAD model is imported into ANSYS environment for FEM analysis; Secondly, establishing the multi-variable coupling finite element model, i.e. carrying out parametric modeling and finite element discretization on CAD model; Thirdly, setting random variables, variable distribution functions and the target function in ANSYS application environment; Fourthly, the input variables are created in a random order with a known probability distribution based on the Monte Carlo method, then the value of target function can be calculated. Fifthly, through comparing the calculation of empirical formula or theoretical formula with the target function value, we can get the statistical characteristic after computing all samples, based on which the product reliability, key parameters sensitivity can be achieved.

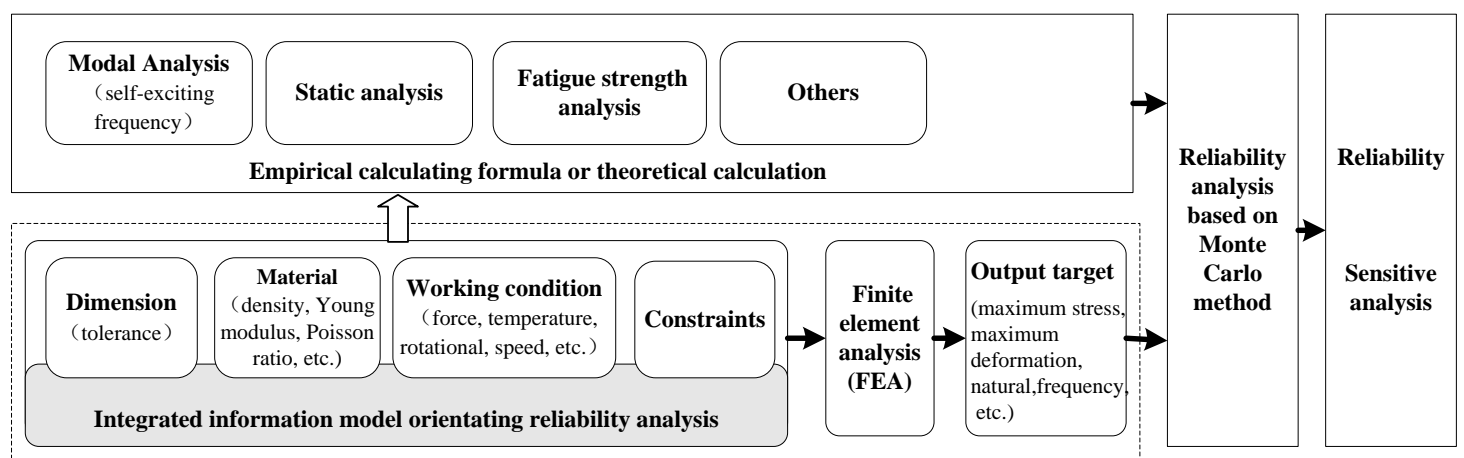

Figure 2. Reliability Analysis based on Multi-variable Coupling Finite Element Model

Actually, ANSYS/PDS module will help complete the reliability analysis effectively, the details are as follows in the case of resonance reliability analysis:

Setp1: Determine the target function in FEA and the number $(\mathrm{N})$ of samples;

Step 2: Defined random variables and their probability distribution type;

Step 3: Generating a group of random numbers;

Step 4: Substitute the random numbers into the finite element control equations to calculate the natural frequency value $f_{0}$, and calculate the self-exciting frequency $f$ according to empirical formula or theoretical formula; 
Step 5: Through comparing $f_{0}$ and $f$, the product performance is considered as reliable if $Z_{-\bmod a l} \leq 0.01$, it counts as 1 and $k=k+1$; otherwise the product performance is considered as resonance vibration failure, it counts as 0 .

Step 6: repeat the above steps 3 and 5 until the total number $(\mathrm{N})$ of samples has been finished.

Step 7: the reliability of target index as can be obtained according to $\mathrm{N}$ time sample function calculation, the reliability is expressed as $P_{S}=P\left[Z_{-\bmod a l} \leq 0.01\right]$.

The above procedure can be generalized to calculate the reliability of yield strength, stressstrength reliability and etc. Based on both sensitivity analysis and relative coefficient analysis, the key influencing factors of product reliability can be determined and then optimized.

\section{Case Study: Resonance Reliability Analysis of Pump Gear System Considering the Influence of Tolerance}

Micro gear pump is commonly used as the driving component of port cleaning instrument, the changing of actual working condition and the existing manufacturing deviation cause wearing condition of gear tooth flank or noise in the process of gears meshing, therefore it is important to carry out resonance vibration analysis, which is based on the self-exciting frequency and the natural frequency value under actual working condition as well as the effect of tolerance.

Nylon MC901 is the material of choice due to its light weight and corrosion resistance properties. Material properties of pump gears are listed in Table 1. The parameters of gear pairs are listed in Table2. In addition, gear pump normal pressure is $2.5 \mathrm{MPa}$, Maximum outputtorque is 1000 N.mm.

Table 1. Properties of Pump Gears

\begin{tabular}{ccc}
\hline Material properties & Unit & Value \\
\hline Density $\left(23^{\circ} \mathrm{C}\right)$ & $\mathrm{kg} / \mathrm{m}^{3}$ & $1.15 \sim 1.17 \times 10^{3}$ \\
\hline Young's modulus & $\mathrm{MPa}$ & $3.2 \times 10^{3}$ \\
\hline Poisson's ratio & - & 0.4 \\
\hline
\end{tabular}

Table 2. Basic Parameters of Gear Pairs

\begin{tabular}{c|c|c|c|c}
\hline $\begin{array}{c}\text { Module } \\
\mathbf{M}(\mathbf{m m})\end{array}$ & $\begin{array}{c}\text { Pressure } \\
\text { angle }\left(^{\circ}\right)\end{array}$ & $\begin{array}{c}\text { Number of } \\
\text { active tooth } \\
\mathbf{z}_{\mathbf{1}}\end{array}$ & $\begin{array}{c}\text { Numberof } \\
\text { driven gear } \\
\mathbf{z}_{\mathbf{2}}\end{array}$ & $\begin{array}{c}\text { Tooth } \\
\text { breadth } \\
\mathbf{B}(\mathbf{m m})\end{array}$ \\
\hline 1.5 & 20 & 10 & 10 & 16 \\
\hline
\end{tabular}

\section{(1) Selecting Design Parameters of Gear}

Because the resonance invalidation of pump gear system happened in process of gears meshing, and the driving gear structure and material properties is similar to driven gear's, so the driving gear was selected for FEA. Building the Finite Element Model of driving gear (Figure 3): to reduce the computational effort of FEA, only part of parametric model with ignored fillet and other small features has been built based on ANSYS / APDL. The 
parametric model grid is based on MESH 200 and using ANSYS eight node SOLID 45 isoparametric elements.

The parameters that affect resonance reliability are randomized, which mainly include tooth breadth(B), gear pitch diameter(D), gear shaft diameter $\left(D_{W}\right)$, gear center distance $\left(A_{W}\right)$, Young modulus(E), left shaft segment (L1), right shaft segment (L3), rotating speed(N), density(MD), Poisson's ratio. They are listed as Table 3.

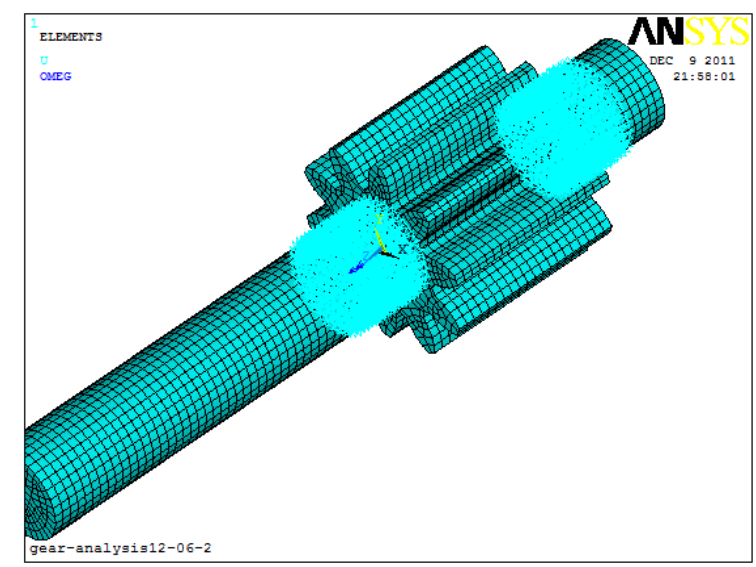

Figure 3. The Finite Element Model of Driving Gear Shaft

Table 3. Random Variables and their Distribution

\begin{tabular}{ccccc}
\hline Random variables & Distribution & $\begin{array}{c}\text { Center } \\
\text { value }\end{array}$ & $\begin{array}{c}\text { Standard } \\
\text { deviation }\end{array}$ & Tolerance \\
\hline $\begin{array}{c}\text { Tooth breadth } \\
(\mathrm{B}) / \mathrm{mm}\end{array}$ & GAUS & 15.865 & 0.045 & $16_{-0.27}^{0}$ \\
\hline $\begin{array}{c}\text { Gear center distance } \\
\left(\mathrm{A}_{\mathrm{W}}\right) / \mathrm{mm}\end{array}$ & GAUS & 15 & 0.03 & $15 \pm 0.09$ \\
\hline $\begin{array}{c}\text { Gear pitch diameter } \\
(\mathrm{D}) / \mathrm{mm}\end{array}$ & GAUS & 14.963 & 0.007 & $\phi 15_{-0.059}^{-0.016}(\phi 15 f 9)$ \\
\hline $\begin{array}{c}\text { Mounting holes } \\
\text { diameter }\left(\mathrm{D}_{\mathrm{W}}\right) / \mathrm{mm}\end{array}$ & GAUS & 7.976 & 0.004 & $8_{-0.035}^{-0.013}(\phi 8 f 8)$ \\
\hline $\begin{array}{c}\text { Left shaft segment } \\
(\mathrm{L} 1) / \mathrm{mm}\end{array}$ & GAUS & 38.16 & 0.053 & $38_{0}^{+0.32}$ \\
\hline $\begin{array}{c}\text { Right shaft segment } \\
(\mathrm{L} 3) / \mathrm{mm}\end{array}$ & GAUS & 10.0 & 0.033 & $10 \pm 0.1$ \\
\hline $\begin{array}{c}\text { Young modulus } \\
(\mathrm{E}) / \mathrm{Mpa}\end{array}$ & GAUS & $3.2 \times 10^{3}$ & 128 & \\
\hline$\rho /$ tonne/mm & GAUS & $1.16 \times 10^{-9}$ & $4.64 \times 10^{-11}$ & \\
\hline$\lambda$ & GAUS & 0.4 & 0.016 & \\
\hline
\end{tabular}




\section{(2) Resonance Reliability Analysis of Gear System based on Monte Carlo-FEM}

According to (8), the self-exciting frequency is calculated as Table 4. According to the result of modal calculation based on Monte Carlo-FEM, the first five order natural frequency has been attained as showed in table 5. By comparing the self-exiting frequency with the natural frequency, which showed that resonance vibration failure probably happened as gear pump runs at rated speed. The resonance vibration happened when $f$ is equal or close to $f_{0 i}, Z_{-\bmod a l}$ is defined as output target and the range of resonance vibration failure is set at $Z_{-\bmod a l} \leq 0.01$.

Table 4. Pump Gear Rotation Speed and Mesh Frequency

\begin{tabular}{cccc}
\hline Working state & $\begin{array}{c}\text { Maximum } \\
\text { speed }\end{array}$ & $\begin{array}{c}\text { Rated } \\
\text { speed }\end{array}$ & $\begin{array}{c}\text { Low } \\
\text { speed }\end{array}$ \\
\hline Speed(r/min) & 4000 & 3200 & 800 \\
\hline $\begin{array}{c}\text { Meshing } \\
\text { frequency (Hz) }\end{array}$ & 666.7 & 533.3 & 133.3 \\
\hline
\end{tabular}

\section{Table 5. The Natural Frequencies of Pump Gear System}

\begin{tabular}{cccc}
\hline $\begin{array}{c}\text { Speed } \\
\text { Order }\end{array}$ & $\begin{array}{c}\text { Maximum } \\
\text { speed }\end{array}$ & $\begin{array}{c}\text { Rated } \\
\text { speed }\end{array}$ & $\begin{array}{c}\text { Low } \\
\text { speed }\end{array}$ \\
\hline 1 & 527.70 & 546.17 & 531.60 \\
\hline 2 & 528.22 & 546.69 & 532.12 \\
\hline 3 & 2387.3 & 2487.8 & 2387.3 \\
\hline 4 & 2846.8 & 2944.3 & 2847.4 \\
\hline 5 & 2849.0 & 2946.5 & 2849.6 \\
\hline
\end{tabular}

\section{(3) Resonance Reliability-based Tolerance Optimization}

According to the defined variables in Table 3, the random parameter sensitivity graph ( Figure 4) and the sensitivity values (Table 6) have been obtained based on Latin hypercube sampling in ANSYS/PSD module. The resonance reliability under the confidence level of $95 \%$ is $67.4 \%$, which showed that the reliability is low and needs to be further optimized.

As showed in Figure 4(a) the target output variable as $Z_{-}$modal has a positive correlation with $\mathrm{L}_{3}, \mathrm{E}, \mathrm{B}$ and POISSON, i.e. the reliability decrease with the increase of these variables; Meanwhile, $\mathrm{Z} \_$modal has a negative correlation with $\mathrm{L}_{1}, \mathrm{D}, \mathrm{D}_{\mathrm{w}}, \mathrm{N}$ and $\mathrm{MD}$, i.e. the reliability decrease with the increase of these variables; $L_{1}, B, L_{3}$ and $D_{W}$ are the main factors that influence the resonance reliability of gear system and can be optimized except for material property parameters. We carry out PDS cycle program again after readjusting the tolerance values of $L_{1}, B, L_{3}$ and $D_{W}$ according to their sensitivity direction, the optimized reliability and new parameters sensitive graph can be obtained as showed in Figure 4(b). 


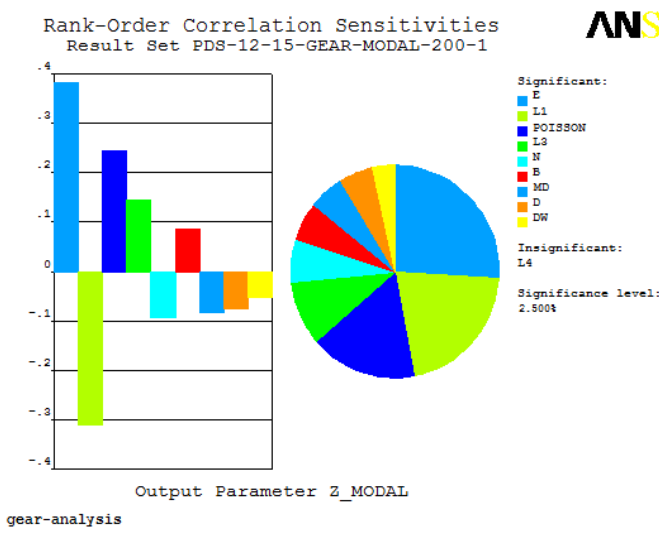

(a) Before tolerance optimization

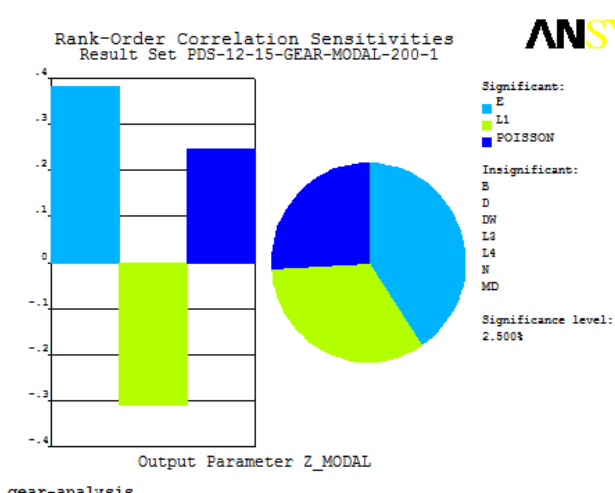

gear-analysis

(b) After tolerance optimization

Figure 4. Random Variables Sensitive Graph

Table 6. The Correlation Coefficient of Random Variables

\begin{tabular}{cccccccccc}
\hline OutIInp & $\mathbf{B}$ & $\mathbf{D}$ & $\mathbf{D}_{\mathbf{W}}$ & $\mathbf{L}_{\mathbf{1}}$ & $\mathbf{L}_{\mathbf{3}}$ & $\mathbf{N}$ & $\mathbf{E}$ & $\mathbf{M D}$ & POISSON \\
\hline Z_modal & 0.085 & -0.075 & -0.053 & -0.310 & 0.144 & -0.094 & 0.381 & -0.083 & 0.244 \\
\hline
\end{tabular}

Table 7. Optimized Tolerance and their Distribution

\begin{tabular}{ccccc}
\hline Random variable & GAUS & $\begin{array}{c}\text { Center } \\
\text { value }\end{array}$ & $\begin{array}{c}\text { Standard } \\
\text { deviation }\end{array}$ & Tolerance \\
\hline $\mathrm{B} / \mathrm{mm}$ & GAUS & 16.135 & 0.045 & $16_{0}^{+0.27}$ \\
\hline $\mathrm{D}_{\mathrm{W}} / \mathrm{mm}$ & GAUS & 7.956 & 0.004 & $\varphi 8_{-0.071}^{-0.013}(\varphi 8 f 10)$ \\
\hline $\mathrm{L}_{1}$ & GAUS & 38 & 0.053 & $38 \pm 0.2$ \\
\hline $\mathrm{L}_{3}$ & GAUS & 10.2 & 0.067 & $10_{0}^{+0.43}$ \\
\hline
\end{tabular}

After tolerance optimization of $\mathrm{B}, \mathrm{D}_{\mathrm{W}}, \mathrm{L}_{1}, \mathrm{~L}_{3}$, the resonance reliability of gear system reached $89 \%$, which is higher than before. Table 7 presents the optimized tolerances and their distribution, Figure 4(b) shows that parts material is also sensitive to the resonance reliability even after tolerance optimization, so the replacing of gear material or adjusting other parameters may contribute to the higher resonance reliability of pump gear system.

\section{Conclusions}

A reliability analysis method considering the influence of tolerance constraints has been proposed and applied to the resonance reliability sensitivity and tolerance optimization of pump gear system. As a matter in fact, there are still several problems requiring further study:

(1) Comprehensive consideration the influence of dimensional and geometric tolerances.

(2) Comprehensive optimization of different reliability indicators including the stressstrength reliability, the resonance reliability and etc.

(3) Multi-objective tolerance optimization considering reliability and cost. 


\section{Acknowledgements}

This work was sponsored by National Natural Science Foundation of China (Grant No. 51405289), Doctoral Fund of the Ministry of Education (Grant No. 20123121120002) and the young teacher training program of Shanghai Municipal Education Commission, China (Grant No.ZZshhs13019).

\section{References}

[1] L. Pierre, D. Teissandier and J. P. Nadeau, "Variational tolerancing analysis taking thermomechanical strains into account: Application to a high pressure turbine", Mechanism and Machine Theory, no. 74, (2014), pp. $82-101$.

[2] D. Xu and Y. Jin, "Performance analysis of the reheat-stop-valve mechanism under dimensional tolerance, misalignment and thermal impact", Strojniski Vestnik/Journal of Mechanical Engineering, vol. 55, no. 9, (2009), pp. 507-520.

[3] I. A. Manarvi and N. P. Juster, "Using FE to simulate the effect of tolerance on part deformation", Published in 9th ISPE CE2002 conference at Cranfield University in July (2002). http://www.ceconf.com/ce2002/: Bedfordshire, UK.

[4] A. Serban, M. Karlsson and S. F. Gong, "Component Tolerance Effect on Ultra-Wideband Low-Noise Amplifier Performance", IEEE Transactions on advanced packaging, vol. 33, no. 3, (2010), pp. 660-668.

[5] Q. Q. Wang, Y. M. Zhang and Z. X. Zhang, "The reliability and sensitivity analysis of the gear random vibration system and transmission error", Journal of Northeastern University: Natural Science, vol. 32, no. 12, (2011), pp. 1741-1744.

[6] Y. N. Wang, Z. L. Sun and Q. Yang, "Study on the gear mode and resonance reliability sensitivity based on thermal analysis", Journal of northeastern university: Natural Science, vol. 34, no. 3, (2013), pp. 408-412.

[7] R. Hochmuth, H. Meerkamm and W. Schweiger, "An Approach to a General View on Tolerances in Mechanical Engineering”, In: Integrated Product Development (Ed. Vajna), Magdeburg, (1998), pp. 65-76.

[8] Q. Song, Y. Zhao and D. Liu, "The application to the method of probabilistic design of Ansys7.0 for structural reliability analysis". China Science and technology paper online, http://www.paper.edu.cn/index.php/default/releasepaper/content/200505-100.pp.1-7, (2005).

[9] W. D. Xu, "Reliability analysis of slope based on Monte Carlo-finite element method", Journal of Fuzhou University (Natural Science), vol. 32, no. 1, (2004), pp. 73-77.

[10] L.Y. Xie, Z. Wang and J. Y. Zhou, "Basic theory and method of mechanical reliability", Beijing: Science Press, (2012).

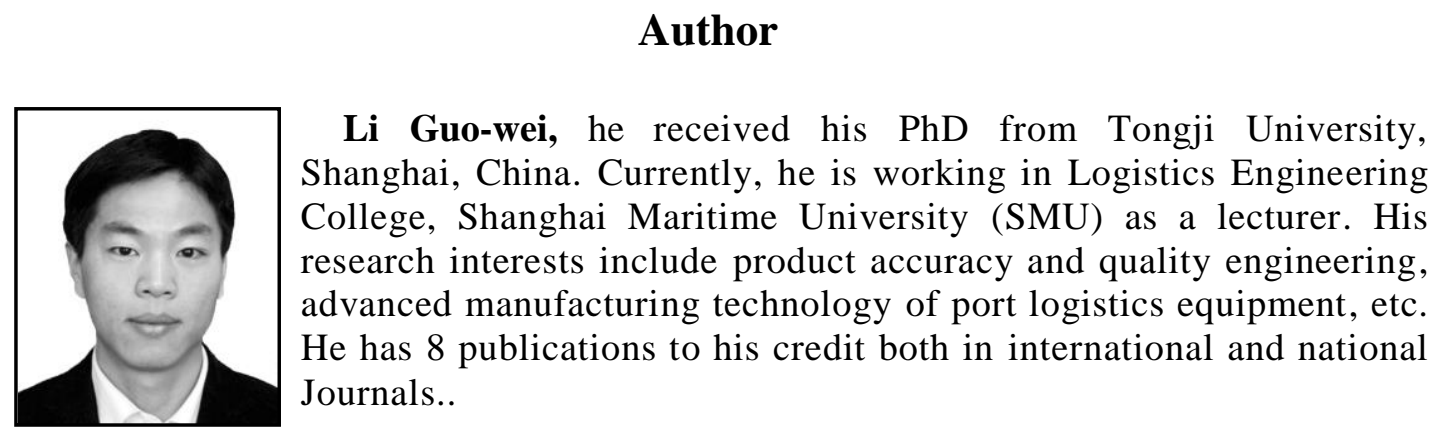


International Journal of Hybrid Information Technology Vol.8, No.2 (2015) 